4th Global Business Research Congress, May 24-25, 2018, Istanbul, Turkey.

\title{
THE EFFECTS OF RISK PROPENSITY ON FINANCIAL WELL-BEING: AN APPLICATION ON BANKING EMPLOYEES
}

DOI: 10.17261/Pressacademia.2018.879

PAP- V.7-2018(32)-p.191-197

Ismail Atabay ${ }^{1}$, Aysegul Yildirim Kutbay², Fatih Karakas ${ }^{3}$, Fatih Koc ${ }^{4}$, Bayram Alamur ${ }^{5}$

${ }^{1}$ Balikesir University, Balikesir, Turkey.

atabay@balikesir.edu.tr, ORCID: 0000-0001-8979-5548

2 Balikesir University, Balikesir, Turkey.

aysegulyildirim@balikesir.edu.tr, ORCID: 0000-0002-3100-2928

${ }^{3}$ Balikesir University, Balikesir, Turkey.

fatih.karakas@balikesir.edu.tr, ORCID: 0000-0002-7982-8454

${ }^{4}$ Kocaeli University, Balikesir, Turkey.

fatih.koc@kocaeli.edu.tr, ORCID: 0000-0002-4751-2340

${ }^{5}$ Balikesir University, Balikesir, Turkey.

alamur bayram@hotmail.com, ORCID: 0000-0002-1364-5604

To cite this document

Atabay, I., Kutbay Yildirim, A., Karakas, F., Koc, A., Alamur, B. (2018). The effects of risk propensity on financial well-being: an application on banking employees. PressAcademia Procedia (PAP), V.7, p.191-197.

Permemant link to this document: http://doi.org/10.17261/Pressacademia.2018.879

Copyright: Published by PressAcademia and limited licenced re-use rights only.

\section{ABSTRACT}

Purpose- One of the most important factors affecting individuals' financial well-being is the financial behaviors of individuals as mentioned in the related studies. The risk propensity is defined as the risk taking tendencies of indivudials in the literature. In the studies conducted, it is seen that as individuals prefer risky investment instruments, risk propensity increase; financialbehaviors affect financial well-being level, while rational financial behaviors increase one's level of financial well-being whereas mismanaged financial processes leave someone with short and long term problems. This study aims to determine the impact of risk propensity on financial well-being.

Methodology- A face-to-face survey was conducted with the employees of the banks located in the Gulf region of Balıkesir Province during the implementation phase of the workshop. The risk propensity scale from the study of Hunjra and Qureshi (2017) and the financial well-being scale developed by Norvilitis, Szablicki and Wilson (2003) used in this study. The data obtained from the questionnaire were subjected to statistical analysis and the results were interpreted. Findings- A negative relationship between the risk propensity and the future financial situation expectation which is one of the sub-dimension of financial wellbeing, was determined in the study. A positive relationship between the present financial situation and the future financial situation expectation which are the sub-dimensions of financial well-being, was also detected. It has been determined that the risk propensity is negatively and low-level influencing the future financial condition expectation which is the sub-dimension of financial well-being.

Conclusion- As a result of the study, it was determined that the risk propensity has a negative and low-level effect on the future financial situation expectation dimension of financial well-being. This situation can be explained that the higher risk propensity increases financial expectations and in terms of future financial situation the individuals see inadequate themselves compared to the higher expectations formed, conversely with lower risk propensity individuals see adequate themselves in terms of future financial situation because of not the higher financial expectation.

Keywords: Risk propensity, financial well-being, banking employees.

JEL Codes: I31, D19, G40

\section{RISK EĞiLiMININ FiNANSAL IYI OLMA HALI ÜZERINDEKi ETKILERI: BANKA ÇALIŞANLARI ÜZERINDE BíR UYGULAMA}

\section{ÖZET}

Amaç- Bireylerin finansal iyi olma halini etkileyen en önemli faktörlerin başında bireylerin finansal davranışlarının yer aldığı, konu ile ilgili yapılan çalışmalarda belirtilmektedir. Risk eğilimi literatürde bireyin risk alma eğilimleri olarak tanımlanmıştır. Yapılan çalışmalarda, bireylerin riskli yatırım araçlarını tercih ettikçe risk eğilimlerinin arttığı, finansal davranış eğilimlerinin finansal iyi olma hali seviyesini etkileyeceği, rasyonel finansal davranışların kişinin finansal iyi olma hali seviyesini arttıracağı, buna karşın yanlış yönetilen finansal sürecin ise, kişiyi kısa ve uzun vadede sorunlarla karşı karşıya bırakacağı ileri sürülmektedir. Bu çalışma, risk eğiliminin finansal iyi olma üzerindeki etkisini tespit etme amacını taşımaktadır.

Yöntem- Çalışmanın uygulama aşamasında Balıkesir ilinin Körfez bölgesinde yer alan bankaların çalışanlarıyla yüz yüze anket çalışması yapılmıştır. Çalışmada Hunjra ve Qureshi (2017) 'nin çalışmasından alınan risk eğilimi ölçeği ile Norvilitis, Szablicki ve Wilson (2003) tarafından geliştirilen finansal iyi olma hali ölçeği kullanılmıștır. Anket çalıșmasından elde edilen veriler istatistiksel analizlere tabi tutulmuş ve sonuçlar yorumlanmıștır.

Bulgular- Çalışmada risk eğilimi ile finansal iyi olma halinin alt boyutlarından gelecekteki finansal durum beklentisi arasında negatif ilişki belirlenmiştir. Finansal iyi olma halinin alt boyutlarından mevcut finansal durum ile gelecekteki finansal durum beklentisi arasında ise pozitif ilişki tespit edilmiştir. Çalışmada risk eğiliminin finansal iyi olma halinin alt boyutlarından gelecekteki finansal durum beklentisi boyutu üzerinde negatif yönde ve düşük düzeyde etkili olduğu belirlenmiştir.

Sonuç- Çalışma sonucunda, risk eğiliminin finansal iyi olma halinin gelecekteki finansal durum beklentisi boyutu üzerinde negatif yönlü ve düşük düzeyde anlamlı bir etkisinin olduğu belirlenmiştir. Bu durum; risk eğilimi yükseldikçe finansal açıdan beklentilerin de artması ve göreceli olarak bu bireylerin yüksek beklentilerine kıyasla kendilerini gelecekteki finansal durum açıdan yetersiz görmesi, tersine risk eğilimi düşük bireylerin finansal açıdan da yüksek bir beklentide olmayarak kendilerini gelecekteki finansal durum açıdan yeterli görmesi şeklinde açıklanabilir.

Anahtar Kelimeler: Risk eğilimi, finansal iyi olma hali, bankacılık sektörü çalışanları. JEL Kodları: I31, D19, G40 


\section{GíRiş}

Latince kökenli bir kelime olan ve Fransızca "risque" kelimesinden türeyen risk kavramını Türk Dil Kurumu "zarara uğrama tehlikesi" olarak tanımlamıştır (TDK, 2018). Buna karşın iş hayatında risk kavramı içine fırsatların da dahil edildiği bir yaklaşım söz konusudur. Ekonomik anlamda risk, iktisadi karar birimlerinin verecekleri kararlar sonucunda ortaya çıkacak getiriyi olumsuz etkileyebilecek olayların gerçekleşme olasılı̆ı anlamına gelmektedir.

Risk eğilimi, Stewart Jr ve Roth (2001) tarafından bireyin risk alma veya riskten kaçınma şeklindeki karar anındaki eğilimi olarak tanımlanmış, yazarlar risk eğiliminin riskli karar alma sürecinde tek başına risk alma davranışına yol açmadığıı ancak önemli bir özellik olarak kabul edildiğini de eklemişlerdir. Linnas'a (2012) göre risk eğilimi, bir kişinin kaybetme ihtimaline karşılık şansını değerlendirmek için ne kadar istekli olduğudur. Bireyin belirsiz sonuçlara sahip durumlarda nasıl devam edileceğine karar verirken risk alma veya riskten kaçınmaya yönelik genel eğilimi genellikle "risk eğilimi" olarak adlandırılan iki karşı̈ özelliktir. Sitkin ve Pablo (1992), karar alıcı bireyin düşük ya da yüksek risk içeren davranışı seçerken bireyin özelliklerinin, sorunun yapısının ve deneyim durumunun etkili olduğunu belirtmişlerdir. Benzer şekilde Saraç ve Kahyaoğlu'na (2011) göre de yatııımcıların risk seviyesine kişilik özellikleri, sosyo-ekonomik faktörler ve psikolojik faktörler etki etmektedir. Erdem (2001) girişimcilerin risk alma eğilimi üzerine yaptı̆̆ı çalışmasında, bireysel özelliklerin, bireyin deneyiminin ve çevresel faktörlerin risk alma eğilimi üzerinde etkili olduğunu savunmuştur.

Literatürde finansal iyi olma hali kavramı, kişinin maddi durumu ile ilgili memnuniyet algısı olarak tanımlanmaktadır (Falahati\&Paim, 2011). Prawitz vd. (2006) finansal iyi olma halini, kişinin kendi finansal durumundan kaynaklanan refah veya stres seviyesinin ifade edilmesi olarak tanımlanmaktadır. Bu kavram; bireyin maddi ve manevi açıdan finansal durumunu nasıl algıladığı, yaşam standartlarını nasıl yükselteceği, kendini finansal açıdan nasıl güvende hissedeceği ve ihtiyaçlarını nasıl karşılayabileceği gibi konuları ön plana çıkarmaktadır (Taft vd., 2013).Finansal iyi olma hali; bireyin ekonomik, çevresel, sosyal, duygusal, bedensel yönlerinin olumlu yansımaları sonucunda oluşmaktadır. Bu bağlamda birey, tüm bu faktörlere dayanarak kendini finansal olarak iyi ya da kötü hissetmektedir (Kutbay vd. , 2017). Bu kavram, her ne kadar bireyin bir özelliği gibi görünse de finansal davranışlarının bir sonucu olarak ortaya çıkmaktadır (Kim , 2000). Sabri ve Falahati (2012) tarafından yapılan araştırmada bireylerin finansal davranış eğilimlerinin finansal iyi olma hali seviyesini etkileyeceğini ileri sürülmüştür.

Finansal iyi olma hali doğası gereği özneldir. Çünkü maddi yönden bireyin kendini nasıl gösterdiğinden ziyade, onun maddi yönünü nasıl algıladığına dayanır. Bu nedenle, aynı gelir düzeyindeki bireyler, kişisel tercihleri ve değerlerine bağlı kalmaları sonucu finansal iyi olma hallerini farklı değerlendirebilirler. Bireyin finansal iyi olma halini nasıl algıladığı kapsamlı bir faktör listesinden etkilenir (Brüggen vd.,2017). Bunlar literatürde; cinsiyet, yaş, eğitim, medeni durum ve aile yapısı gibi kişisel demografik özellikler(Joo ve Grable, 2004; Malone vd., 2010); finansal bilgi ve etkinliği (Shim vd., 2009; Vosloo vd., 2014) ; para ya da borç gibi konulara yönelik finansal tutumlar (Norvilitis vd., 2003); materyalizm gibi finansal eğilimler, risk eğilimi ve risk alma isteği (Gutter ve Copur, 2011); bütçeleme, tasarruf ve zorlayıcı satın alma gibi alanlardaki finansal davranışlar (Joo ve Grable, 2004; Shim vd.,2009) olarak belirtilmektedir.

\section{ARAŞTIRMA}

\subsection{Araştırmanın Amacı}

Bu araştırmanın amacı banka çalışanlarında risk eğiliminin finansal iyi olma hali üzerindeki etkisini tespit etmektir. Banka çalışanları, hizmet verdikleri müşterilerine yatııım kararlarında yol göstermekte ve onların yatıım kararları üzerinde etkili olmaktadırlar. Banka gibi yatıım olanaklarının geniş olduğu bir sektörde çalışan bireylerin, kendi portföylerini oluştururken yaptıkları tercihler sonucunda kendilerini finansal yönden ne durumda görmekte olduklarının ve risk eğilimlerinin tespit edilerek, risk eğiliminin finansal iyi olma hali üzerindeki etkisini tespit etmek bu çalışmaya ayrı bir önem katmaktadır.

\subsection{Araştırmanın Hipotezleri ve Modeli}

Araştırmanın amacını ifade eden model Şekil-1'de sunulmuştur.

\section{Şekil 1: Araştırmanın Modeli}

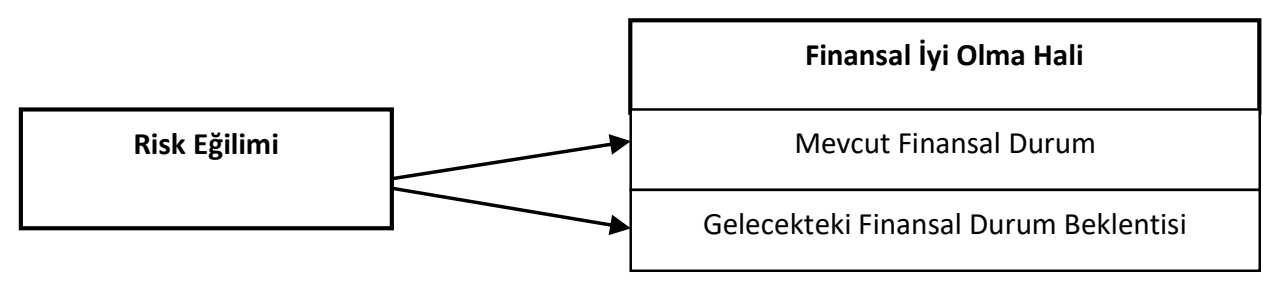

Araştırmanın modeline uygun olarak aşağıdaki hipotezler geliştirilmiştir.

H1: Risk Eğiliminin Finansal İyi Olma Halinin Mevcut Finansal Durum boyutu üzerinde anlamlı bir etkisi vardır

H2: Risk Eğiliminin Finansal İyi Olma Halinin Gelecekteki Finansal Durum Beklentisi boyutu üzerinde anlamlı bir etkisi vardır. 


\subsection{Araştırmanın Sınırlılıkları}

Bu araştırma Balıkesir ili Körfez bölgesinde (Edremit, Burhaniye, Gömeç, Ayvalık) faaliyet gösteren bankalarda çalışanlar üzerinde yapılmış olup, ülkemizin diğer bölgelerindeki banka çalışanlarının zaman ve imkanlar nedeniyle araştırmaya dahil edilememiş olması bu araştırmanın kısıtlarını oluşturur.

\subsection{Araştırmanın Örneklemi}

Balıkesir ili Körfez bölgesinde (Edremit, Burhaniye, Gömeç, Ayvalık) faaliyet gösteren bankalarda çalışanlar bu araştırmanın ana kütlesini oluşturmaktadır. Anket uygulaması için kolayda örnekleme metodu seçilmiş ve uygulama yüz yüze yapılarak gerçekleştirilmiştir. Araştırma kapsamında araştırmaya katılmayı kabul eden 290 banka çalışanı ile görüşülmüştür. Eksik bilgi verilen 24 anket araştırmaya dahil edilmeyerek, 266 anket veri analizinde kullanılmıştır.

\subsection{Araştırmada Kullanılan Veri Toplama Araçları ve Verilerin Analizi}

Araştırmanın değişkenlerinden Finansal İyi Olma Hali Ölçeği (FiHÖ) Norvilitis, Szablicki ve Wilso'nun (2003) yılındaki çalışmasından uyarlanmış olup 8 sorudan oluşmaktadır. Araştırmada, Nosic ve Weber (2010) tarafından geliştirilip Hunjra, Qureshi ve Riaz (2017) tarafından uyarlanarak kullanılmış olan Risk Eğilimi Ölçeği (RE) kullanılmış olup, ölçek 6 sorudan oluşmaktadır.

Finansal iyi olma hali ve risk eğilimi ölçeklerindeki ifadelerden her biri; (1) Kesinlikle Katılmıyorum , (2) Kısmen Katılmıyorum, (3) Kararsızım, (4) Kısmen Katılıyorum, (5) Tamamen Katılıyorum olmak üzere 5 basamaklı likert tipi puanlanmıştır. Ölçeklerdeki ters (reverse) ifadelere verilen cevaplar $5 \rightarrow 1,4 \rightarrow 2,3 \rightarrow 3,2 \rightarrow 4,1 \rightarrow 5$ olacak şekilde kodlanmıştır.

Verilerin analizinde SPSS 22 ve AMOS paket programları kullanılmıştır.

\section{ARAŞTIRMA BULGULARI VE VERILERIN ANALIZi}

\subsection{Demografik Faktörlere iliş̧kin Bulgular}

Aşağıdaki Tablo 1'de ankete katılan banka çalışanlarının demografik özelliklerini gösteren frekans dağılımları görülmektedir.

Tablo 1: Cevaplayıcıların Demografik Özelliklerine ilişkin Değerler

\begin{tabular}{lll}
\hline Cinsiyet & Frekans & Yüzde \\
\hline Kadın & 135 & 50,8 \\
Erkek & 131 & 49,2 \\
Toplam & 266 & 100,0 \\
\hline Yaș & Frekans & Yüzde \\
\hline 25 ve Altı & 11 & 4,1 \\
$26-30$ & 63 & 23,7 \\
$31-35$ & 94 & 35,3 \\
$36-40$ & 52 & 19,5 \\
$41-45$ & 28 & 10,5 \\
46 ve Üstü & 18 & 6,8 \\
Toplam & 266 & 100,0 \\
\hline & &
\end{tabular}

\begin{tabular}{lll}
\hline Medeni Durum & Frekans & Yüzde \\
\hline Evli & 188 & 70,7 \\
Bekar & 78 & 29,3 \\
Toplam & 266 & 100,0 \\
\hline Öğrenim Düzeyi & Frekans & Yüzde \\
\hline Lise & 21 & 7,9 \\
Ön Lisans & 29 & 10,9 \\
Lisans & 199 & 74,8 \\
Yüksek Lisans & 17 & 6,4 \\
Toplam & 266 & 100,0 \\
& & \\
& &
\end{tabular}

\begin{tabular}{lll}
\hline Calıșlan Birim & Frekans & Yüzde \\
\hline Bireysel & 66 & 24,8 \\
Gişe & 56 & 21,1 \\
Kobi & 54 & 20,3 \\
Müdür & 25 & 9,4 \\
Operasyon & 65 & 24,4 \\
Toplam & 266 & 100,0 \\
\hline Calıșllan Pozisyon & Frekans & Yüzde \\
\hline Müdür & 25 & 9,4 \\
Yetkili & 157 & 59,0 \\
Yönetmen & 84 & 31,6 \\
Toplam & 266 & 100,0 \\
\hline
\end{tabular}

\subsection{Geçerlilik ve Güvenirlilik}

Araştırmada kullanılan ölçeklerin geçerlilikleri için açıklayıcı ve doğrulayıcı faktör analizleri yapılmıştır. Bunun yanı sıra, her ölçeğin AVE (AverageVarianceExtract) değerleri sunularak yakınsak (convergent) geçerliliğin var olup olmadığı araştırılmıştır. Güvenilirlik için, ölçeklerin Cronbach's Alpha ve CR (CompositeReliability) değerleri sunulmuştur.

\subsection{Araştırmada Kullanılan Ölçeklere İlişkin Açıklayıcı ve Doğrulayıcı Faktör Analizleri}

Finansal İyi Olma Hali Ölçeği ve Risk Eğilimi Ölçeği literatürde birçok kez ele alınıp incelenmiştir. Birçok farklı ülkede ve farklı örneklem üzerinde ölçeğin geçerlilik ve güvenilirliği test edilmiştir. Bu noktada, ölçeğin bu çalışma için kullanılıp kullanılamayacağını belirlemek için önce Açıklayıcı Faktör Analizi (AFA), sonra da doğrulayıcı faktör analizi (DFA) yapılmıştır. Analiz sonuçları aşağıdaki Tablo-2'de sunulmuştur.

Ölçeğin boyutlarının güvenirliliğini belirlemek için her boyut için alfa katsayısı hesaplanmıştır. Boyutların alfa katsayılarının 0,70'ın üstünde olması yeterli derecede güvenirlilik koşulunun karşılandığını göstermektedir (İslamoğlu ve Alnıaçık, 2016). Özdeğeri 1'den büyük olan faktörler dikkate alınmıştır. Ölçeğin açıklanan toplam varyans değeri 57,304 olarak belirlenmiştir. Yapılan Açıklayıcı Faktör Analizi (AFA) sonucunda, Finansal iyi Olma Hali ölçeğinin orijinal çalışma ile uyumlu olarak iki boyuttan oluştuğu, Risk Eğilimi ölçeğinin ise yine orijinal çalışma ile uyumlu tek boyuttan oluştuğu görülmektedir. 
Tablo 2: Açıklayıcı ve Doğrulayıcı Faktör Analizi Sonuçları

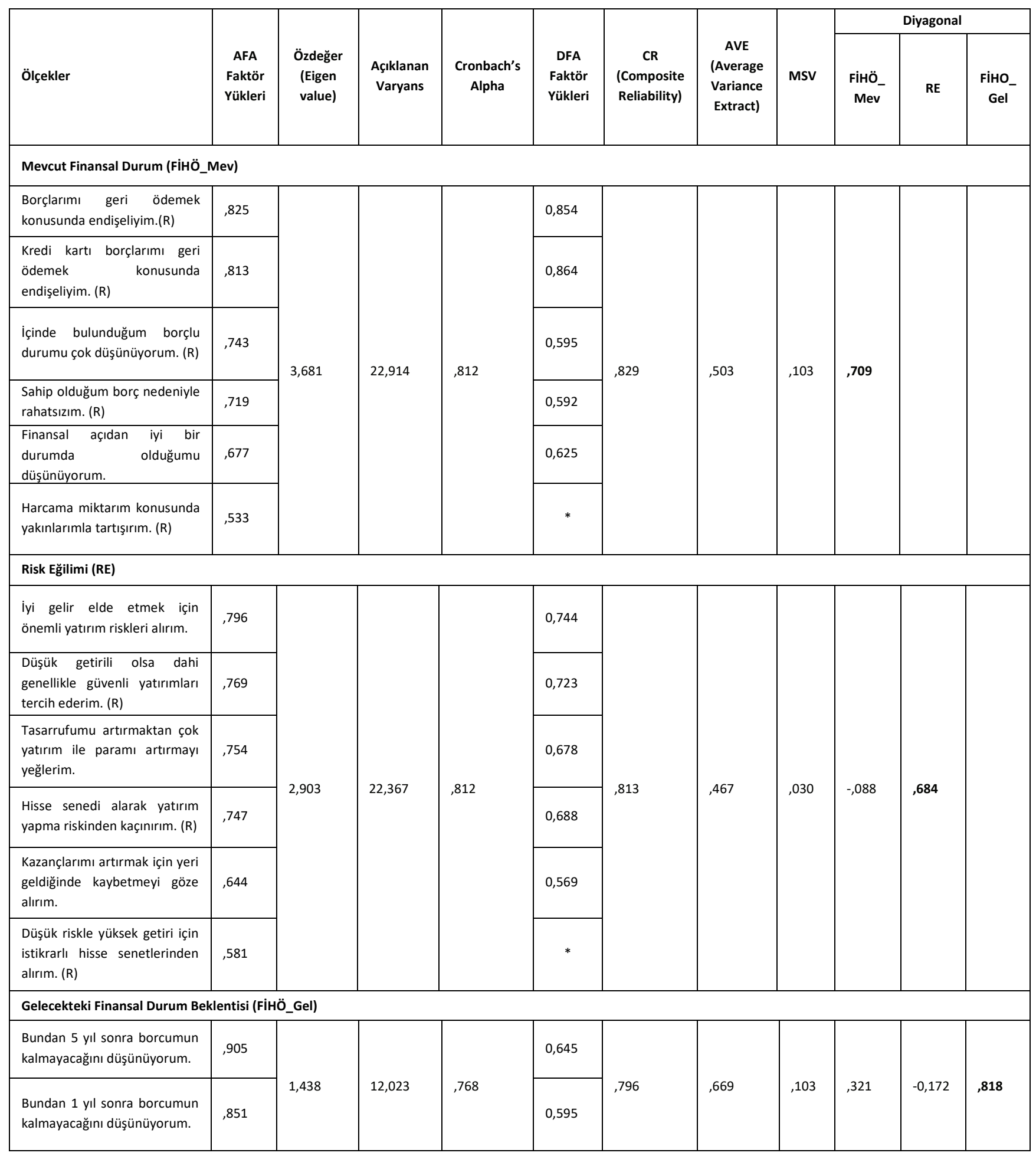




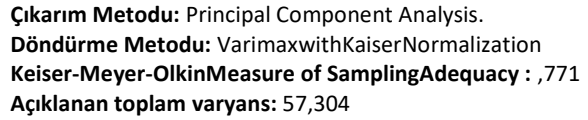

* Faktör yapısını bozduğu veya düşük faktör yüküne sahip olduğu için ölçekten çıkarılmıştır.

Model Uyum Değerleri

CMIN/DF= 1,754; CFI= 0,966; GFI= 0,946; SRMR= 0,066; RMSEA= 0,053

Ancak, bu sonucun doğrulanmasına intiyaç vardır. Bu nedenle, araştırmanın bu aşamasında Doğrulayıcı Faktör Analizi (DFA) yapılmıştır. DFA'da Finansal İyi Olma Hali(FiHÖ) ölçeğinde bir ifade, Risk Eğilimi (RE) ölçeğinde de bir ifade faktör yapısını bozduğu veya düşük faktör yüküne sahip olduğu için ölçekten çıkarılmıştır. CR değerleri ölçeklerin güvenirlilik düzeylerini gösterir ve değerlerin 0,70 'in üzerinde olması istenir ( Hair, Black, Babin ve Anderson , 2010; Gaskin, 2018).Tablodaki değerler incelendiğinde, tüm ölçeklerin güvenilir olduğu söylenebilir. Bunun yanı sıra, geçerlilik için, ölçeklerin AverageVarianceExtract (AVE) değerlerinin de 0,50'nin üstünde olması istenir(Hair vd. 2010; Gaskin, 2018). Mevcut Finansal Durum (FiHÖ_Mev) ve Gelecekteki Finansal Durum Beklentisi (FiHÖ_Gel) değişkenlerinin geçerlilik için istenilen düzeyde olduğu görülmektedir. Ancak, Risk Eğilimi (RE) değişkeninin AVE değeri 0,467 olup, 0,50’ye çok yakın olduğu görülmektedir. Bu nedenle, MSV ve AVE değerlerinin kök dışına çıkmış hali olan diyagonal bölümdeki sayılar incelenmelidir. Bu değer 0,684 olarak görülmekte olduğundan Risk Eğilimi (RE) değişkeni için de geçerliliğin olduğu kabul edilmelidir. MSV değerlerinin AVE değerlerinden küçük çıkması istenir. Tablo 2'deki değerler incelendiğinde, tüm MSV değerlerinin AVE değerlerinden küçük olduğu görülmektedir. Diyagonal bölümde bulunan AVE değerlerinin kök dışına çıkmış hali olan sayılar, içerdeki değişkenler arasındaki korelasyon değerlerinden $(0,321,-0,172$ ve $-0,088)$ büyük olmalıdır. Her iki durumunda istenilen seviyede çıkması ile ölçeklerin discriminant geçerliliğini sağladığı söylenebilir.

Ölçeklerin geçerlilik ve güvenilirliği sağlandıktan sonra, değişkenler arasındaki ilişkileri (korelasyon) ve bazı tanımlayıcı istatistikleri incelemek yerinde olacaktır. Bu amaçla aşağıdaki Tablo-3 hazırlanmıştır.

Tablo 3: Değişkenler Arasındaki Korelasyonlar ve Bazı Tanımlayıcı İstatistikler

(1) Risk Eğilimi (RE)

(2) Mevcut Finansal Durum (FiHÖ_Mev)

\begin{tabular}{llll}
$(1)$ & $(2)$ & Ortalama & Std. Sapma \\
\hline,- 085 & & 2,8064 &, 82899 \\
,$- 138^{*}$ &, $255^{* *}$ & 3,8064 &, 90526 \\
& & 3,2368 & 1,25454
\end{tabular}

$* * \mathrm{p}<0.01 * \mathrm{p}<0.05$

Analiz sonuçlarına göre; "Risk Eğilimi (RE)" ile Finansal İyi Olma Hali alt boyutlarından"Gelecekteki Finansal Durum Beklentisi (FiHÖ_Gel)"arasında p<0.05 anlamlılık düzeyinde negatif ilişki elde edilmiştir. Finansal İyi Olma Hali alt boyutlarından “Mevcut Finansal Durum (FiHÖ_Mev)" ile "Gelecekteki Finansal Durum Beklentisi (FiHÖ_Gel)"arasında ise p<0.01 anlamlılık düzeyinde pozitif ilişki elde edilmiştir.

\subsection{Hipotezlerin Testi}

Araştırmanın modeline uygun olarak kurulan hipotezlerin test edilmesi için Yapısal Eşitlik Modellemesi yöntemi AMOS programı kullanılmıştır. Test sonuçları aşağıdaki Tablo 4'de sunulmuştur.

Tablo 4: Hipotezlerin Testi

\begin{tabular}{lllcccc}
\hline Değişkenler & & & Std. Regresyon Katsayısı & t değeri & $\mathrm{P}$ & $\mathrm{R}^{2}$ \\
\hline FiHÖ_Mev & $<---$ & Risk Eğilimi & $-0,097$ & $-1,319$ &, 187 & 0,009 \\
FiHÖ_Gel & $<---$ & Risk Eğilimi & $\mathbf{- 0 , 1 5 7}$ & $\mathbf{- 2 , 4 9 0}$ & $\mathbf{, 0 1 3 *}$ & $\mathbf{0 , 0 2 5}$ \\
\hline * & & & & & &
\end{tabular}

Tablo incelendiğinde, risk eğiliminin $(P=0,013)$ finansal iyi olma halinin gelecekteki finansal durum beklentisi boyutu üzerinde negatif yönde etkili olduğu görülmektedir. Risk eğiliminin, finansal iyi olma halinin mevcut finansal durum boyutu üzerinde ise etkili olmadığı tespit edilmiştir. Bu sonuçlardan hareketle; $\mathrm{H} 2$ hipotezi kabul edilirken, $\mathrm{H} 1$ hipotezi desteklenmemiştir.

\section{SONUÇ}

Bu çalışma, banka çalışanlarında risk eğiliminin finansal iyi olma hali üzerindeki etkisini tespit etme amacıyla yapılmıştır. Banka çalışanlarının hizmet verdikleri müşterilerine yatırım kararlarında yol göstermeleri ve onların yatırım kararları üzerinde etkili oluşu bu çalışmaya ayrı bir önem katmaktadır.

Araştırma sonuçlarına göre, bankacılık çalışanlarının risk eğilimi puanının 2,8064 olduğu, mevcut finansal durum puanının 3,8064 olduğu, gelecekteki finansal durum beklentisi puanının ise 3,2368 olduğu görülmektedir. Gelecekteki finansal durum beklentisi puanının mevcut finansal durum puanından düşük oluşu, araştırmanın yapıldığı döneme ilişkin genel ekonomik durumla ilgili olabilir ve farklı bir ekonomik konjonktürde farklı sonuçlara ulaşılabilir. 
Çalışmada Risk Eğilimi (RE) ile Finansal İyi Olma Hali alt boyutlarından “Gelecekteki Finansal Durum Beklentisi (FiHÖ_Gel)”arasında p<0.05 anlamlılık düzeyinde negatif ilişki elde edilmiştir. Finansal İyi Olma Hali alt boyutlarından "Mevcut Finansal Durum (FiHÖ_Mev)" ile “Gelecekteki Finansal Durum Beklentisi (FiHÖ_Gel)” arasında ise $\mathrm{p}<0.01$ anlamlılık düzeyinde pozitif ilişki elde edilmiştir.

Çalışmada risk eğiliminin $(P=0,013)$ finansal iyi olma halinin gelecekteki finansal durum beklentisi boyutu üzerinde negatif yönde ve düşük düzeyde $\left(R^{2}=, 025\right)$ etkili olduğu belirlenmiştir. Bu durum, risk eğilimi azaldıkça gelecekteki finansal durum beklentisinin arttığı, tersine risk eğilimi arttıkça gelecekteki finansal durum beklentisinin azaldığı anlamına gelmektedir. Kendilerini gelecekteki finansal durum açıdan yeterli görmeyenler, daha fazla risk eğilimi göstermektedirler. Bu sonuç, araştırmanın yapıldığı döneme ilişkin ekonomik konjonktürle de açıklanabilir. Çalışmada risk eğiliminin, finansal iyi olma halinin mevcut finansal durum boyutu üzerinde ise etkili olmadığı tespit edilmiştir.

Araştırmamız Balıkesir ili Edremit Körfezi bölgesinde (Edremit, Burhaniye, Gömeç, Ayvalık, Havran) faaliyet gösteren bankalardaki çalışanlar üzerinde yapılmış olup, ülkemizin diğer bölgelerinde faaliyet gösteren banka çalışanları üzerinde de benzer araştırmaların yapılması gelecekteki araştırmacılara önerilmektedir.

\section{KAYNAKÇA}

Brüggen, E., Hogreve, J., Holmlu, M., Kabadayi, S., Löfgren, M. (2017). Financial well-being: a conceptualization and research agenda. Journal of Business Research, 79, 228-237.

Erdem, F. (2001). Girişimcilerde risk alma eğilimi ve belirsizliğe tolerans ilişkisine kültürel yaklaşım. Akdeniz University Faculty of Economics \& Administrative Sciences Faculty Journal/Akdeniz Universitesi Iktisadi ve Idari Bilimler Fakultesi Dergisi, 1(2), 43-61.

Falahati, L., Paim, L. (2011). Gender differences in financial well-being among college students. Australian Journal of Basic and Applied Sciences, 5(9), 1765-1776.

Gaskin, J. (2018). Confirmatory factor analysis. Gaskination's StatWiki, http://statwiki.kolobkreations.com, (Erişim Tarihi: 15.05.2018)

Gutter, M., Fontes, A. (2006). Racial differences in risky asset ownership: a two-stage model of the investment decision-making process. Journal of Financial Counseling and Planning,, 17(2), 64-78.

Gutter, M., Copur, Z. (2011). Financial behaviors and financial well-being of college students: evidence from a national survey. Journal of Family and Economic Issues, 32(4), 699-714.

Hair, J., Black, W., Babin, B., Anderson , R. (2010). Multivariate data analysis (7. baskı b.). Pearson.

Hunjra, A., Qureshi, Riaz, L. (2017). Psychological factors and investment decision making: a confirmatory factor analysis. Journal of Contemporary Management Sciences, 2(1), 65-82.

İslamoğlu, A. H., Alnıaçık, Ü. (2016). Sosyal bilimlerde araştırma yöntemleri. Genişletilmiş 5. Baskı, Beta Yayınevi.

Joo, S., Grable, J. (2004). An exploratory framework of the determinants of financial satisfaction. Journal of Family and Economic Issues, 25(1), 25-50.

Kim, J. (2000). The effects of workplace financial education on personal finances and work Unpublished doctoral dissertation. Virginia Polytechnic Institute and State: Blacksburg.

Kutbay, A., Özbek, V., Koç, F. (2017). Kişisel faktörler ve postmodern tüketim şekillerinin finansal iyi olma hali üzerindeki etkisi. In Proceedings of 2 nd International Conference on Scientific Cooperation for the Future in the Economics and Administrative Sciences , 262273.

Linnas, A. (2012). Risk propensity of corporate financial executives: cross-country comparison. (Doctoral dissertation, Tartu Ülikool).

Malone, K., Stewart, S., Wilson, J., Korschi, P. (2010). Perceptions of financial well-being among American women in diverse families. Journal of Family and Economic Issues, 31(1), 63-81.

Norvilitis, J., Szablicki, B., Wilson, S. D. (2003). Factors influencing levels of credit-card debt in college students. Journal of Applied Social Psychology, 33(5), 935-94.

Nosic, A., Weber, M. (2007). Determinants of risk taking behavior: the role of risk attitudes, risk perceptions and beliefs. University at Mannheim, SFB 504,(07-56), 1-33.

Prawitz, A., Garman, E., Sorhaindo, B., O’Neill, B., Kim, J., Drentea, P. (2006). InCharge financial distress/ financial well-being scale: development, administration, and score interpretation. Financial Counseling and Planning, 17(1), 34-50.

Sabri, M., Falahati, L. (2012). Estimating a model of subjective financial well-being among college students. International Journal of Humanities and Social Science, 2(18), 191-199.

Saraç, M., Kahyaoğlu, M. (2011). Bireysel yatırımcıların risk alma eğilimine etki eden sosyo-ekonomik ve demografik faktörlerin analizi. Journal of BRSA Banking \& Financial Markets, 5(2), 135- 157. 
Shim, S., Xiao, J., Barber, B., Lyons, A. (2009). Pathways to life success: a conceptual model of financial well-being for young adults. Journal of Applied Developmental Psychology, 30(6), 708-723.

Sitkin, S., Pablo, A. (1992). Reconceptualizing the determinants of risk behavior. Academy of Management Review, 17(1), 9-38.

Stewart Jr, W., Roth, P. (2001). Risk propensity differences between entrepreneurs and managers: a meta-analytic review. Journal of Applied Psychology, 86(1), 145-153.

Taft, M., Hosein, Z., Mehrizi, S., Rosha, A. (2013). The relation between financial literacy, financial wellbeing and financial concerns. International Journal of Business and Management, 8(11), 63-75.

TDK (2018). Genel Türkçe sözlük, Türk Dil Kurumu, http://www.tdk.gov.tr/index.php?option=com_gts, (Erişim Tarihi: 17.05.2018).

Vosloo, W., Fouche, J., Barnard, J. (2014). The relationship between financial efficacy, satisfaction with remuneration and personal financial well-being. International Business and Economics Research Journal, 13(6), 1455-1470. 